\section{To discard or to ado(a)pt? Looking at qualitative research templates through the lens of organizational routines}

\author{
Lakshmi Balachandran Nair \\ Department of Business and Management, LUISS Guido Carli University, Rome, Italy
}

Qualitative research templates

\begin{abstract}
Purpose - Many management scholars view templates as rigid rulebooks suffocating qualitative research. This viewpoint article recommends that, instead, templates should be viewed through the lens of organizational routines.

Design/methodology/approach - To facilitate this viewpoint, this article first clarifies the confusions surrounding templates. It points out that how using templates, like following routines in an organization, constitutes three parts - the artifact, the ostensive and the performative; the latter two being often neglected by template critics. The use of templates is encouraged by discussing the learning advantages for novice researchers, through an autoethnographic note narrating the author's own research and teaching experiences. Findings - This article deliberates upon the criticisms against templates. It then discusses templates using a perspective offered by organizational routines. Thereafter, the use of templates in qualitative management research is discussed, with the help of examples from published reports. Finally, the article explains a way of reflexively using templates through an autoethnographic note detailing the author's own research and teaching experiences.

Originality/value - In its entirety, the article submits that the artifacts offered by the templates and the ostensive and performative engagements of the template-users must co-exist for co-creating excellent qualitative research.
\end{abstract}

Keywords Templates, Checklists, Qualitative methodology, Organizational routines, Ostensive part, Performative part, Artifacts

Paper type Viewpoint

Templates in qualitative management research have seen much popularity in the past. Researchers were content to have templates (also known as boiler plates, quality standards, best-practice recommendations, systematic approaches, consolidated reporting criteria, etc.) which assisted them in conducting qualitative studies and curbing "sleight of hand" reporting (Manuj and Pohlen, 2012, p. 790). Following this line of thought, various researchers developed templates for conducting and reporting qualitative management research (e.g. Kaufmann and Denk, 2011; Orton, 1997). However, quite contrary to this line of thought, most interpretivistic and postmodern qualitative researchers nowadays consider the use of templates as a limiting factor (e.g. Denzin, 2009; Weatherall, 2019). Some critics comment on how the flexibility and adaptability of qualitative research will be affected if authors apply a template in their studies or reports. In their opinion, templates might act as "technical fixes" or "bumper stickers of approval" and would thereby convert researchers into "glorified reporters" rather than "interpreters and critical evaluators" (Barbour, 2001, p. 1116).

(C) Lakshmi Balachandran Nair. Published by Emerald Publishing Limited. This article is published under the Creative Commons Attribution (CC BY 4.0) licence. Anyone may reproduce, distribute, translate and create derivative works of this article (for both commercial and non-commercial purposes), subject to full attribution to the original publication and authors. The full terms of this licence may be seen at http://creativecommons.org/licences/by/4.0/legalcode

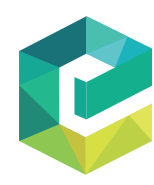

Qualitative Research in Organizations and Management An International Journal Vol. 16 No. 2, 2021 pp. $409-423$

Emerald Publishing Limited 1746-5648 DOI 10.1108/QROM-09-2020-2021 
QROM

16,2
In fact, a recent special issue of Organizational Research Methods journal addresses the adverse consequences of using templates in qualitative research (Köhler et al., 2019). Individual articles in this particular special issue discuss various aftermaths of using templates, such as their inadequacy to address the fundamental challenges of interpretation (Mees-Buss et al., 2020), inability to represent analytic procedures and incapacity to articulate the researchers' analytic actions (Locke et al., 2020). Further articles in the special issue discuss how templates enable protocolization of qualitative research procedures by offering themselves as substitutes for rigor (e.g. Harley and Cornelissen, 2020). The main premise of these discussions is the notion that researchers blindly follow the templates which hold them back from creating interesting and rigorous research. In this viewpoint article, I will first deliberate upon this notion as well as the resultant criticisms against templates. Then I will discuss templates using a perspective offered by organizational routines. Thereafter, I will discuss the use of templates in qualitative management research, with the help of examples from published articles. Finally, I will explain one way of reflexively using templates, through an autoethnographic note detailing my own research and teaching experiences.

\section{Developing a new understanding of qualitative research templates}

The feature topic of the aforementioned Organizational Research Methods special issue discusses how the use of templates creates an expectation of what qualitative methods should look like, what they should entail and how they should be written up (Köhler et al., 2019). Instead, Buus and Perron (2020) explain how the use of templates assist the researchers in designing and conducting rigorous studies, reporting their completed studies or assessing the rigor and comprehensiveness of studies conducted by others (Buus and Perron, 2020). If we examine these two statements, it is clear that the term "template" is understood differently by these two author teams. The latter statement discusses how a template could (not must) assist (not impose upon) the researchers with a particular way of undertaking certain research-related measures. In the former statement, the template is supposedly creating expectations about what certain research-related measures should look like.

The templates being discussed in these two statements appear to be of different scope. Similarly, these two statements alone discuss different uses of templates (e.g. designing, conducting, reporting, checking rigor and so on). This suggests that templates in qualitative research are often created not with one, but multiple purposes. It is crucial to understand the purpose of a specific template before making any decisions regarding its use. I do concur that the rigid rule books on reporting will lead to standardized, formalized accounts of the research procedures and that they should be replaced with more praxis-oriented approaches (Nair, 2020). At the same time, the use of well-established templates has assisted inexperienced or novice researchers in conducting their investigations in a recognizable, socially appropriate manner that is consistent with the widely held norms of qualitative research (Sonpar et al., 2010).

Furthermore, certain other templates promote transparency by helping researchers narrate the diversity and entirety of their investigations within the word/page limits set by journals (Weiss et al., 2015; Nair, 2020). I think that the use of templates should therefore not be considered taboo altogether, since its use can contribute to better designing, conducting and understanding of qualitative studies. By promoting transparency, recognizability and consistency, templates contribute to the legitimacy-seeking behaviors of qualitative researchers. A critic of templates might point out that this legitimacy-seeking is an adverse effect of templates. Indeed, blind and unreflexive use of templates would reduce the need for intellectual reasoning and result in a taken-for-granted, paint-by-numbers approach to qualitative research. However, this standpoint assumes that all template users apply templates blindly and rigidly (and all nontemplate users do not follow research procedures 
blindly). In my viewpoint, the uncritical, unreflexive application of templates is caused due to a misunderstanding, i.e. the assumption that templates are to be rigidly followed. However, more often than not, this is not the case.

As rightfully noted in the aforementioned Organizational Research Methods special issue, qualitative research is diverse, flexible and applicable to various management topics and situations, all while constantly developing and advancing itself (Köhler et al., 2019). Despite the aforesaid aversion to templates by various members of the community, qualitative researchers use templates in their everyday life. To give an example, Eisnehardt's article offering a template for building theories from case study research has been cited more than 61,500 times (Eisenhardt, 1989; Google Scholar, 2021; Langley and Abdallah, 2011). From the sampling matrix to the coding scheme, templates in different forms are used across different qualitative methods. Except in the case of certain very specific templates like the COREQ (consolidated criteria for reporting qualitative research by Tong et al., 2007), which focuses on reporting interviews and focus group studies only, templates for designing and conducting qualitative studies are usually diverse and abstract enough to guide researchers through varied paths of action and circumstances.

For instance, the Joanna Briggs Institute offers a set of criteria which help a qualitative research synthesizer critically appraise the suitability of data for inclusion in the analysis (Joanna Briggs Institute, 2017). The template offered is abstract, with one of the items being a probing question about the congruity of the research methodology with the stated philosophical perspective. A template such as the Johanna Briggs Critical Appraisal Checklist is flexible to accommodate diverse research actions and curb their mechanistic application. It is the researcher who decides which concrete research actions to execute so as to ensure methodological quality. This leads us to an important question - How can we promote this kind of nonmechanistic and unrepetitive use of templates? In my opinion, a shift from thinking about templates as rigid rule books to templates as systems capable of change is fundamental in curbing their mechanistic usage. I discuss this potential shift further by examining templates through the lens of organizational routines.

\section{Organizational routines and templates}

Routines are habitual performances of established procedures (Webster, 2020). Organizational routines, in particular, are conceptualized as mechanisms, which ensure accomplishment of tasks and accountability in an organization. These routines are recognizable patterns of interdependent tasks carried out by various actors for fulfilling organizational tasks (Becker, 2004). For instance, let us consider the hiring routine in a company. This routine involves a series of interdependent tasks such as attracting potential candidates, screening and choosing a certain number of these candidates for the interview, making decisions regarding the candidates and communicating the decisions to them (Feldman and Pentland, 2003). Similarly, templates provide a series of suggestions or options for conducting various actions or steps in the research process (e.g. Anderson, 2010; Tong et al., 2007). Theory building by means of qualitative methods often displays an interdependence between emerging theory, empirical data and the research process (Glaser, 1978; Glaser et al., 1968; Kaufmann and Denk, 2011; Strauss and Corbin, 1998; Van Maanen et al., 2007). To give an example, the Eisenhardt template suggests a series of interdependent and often iterative tasks such as defining the research question, theoretically sampling cases, crafting instruments and protocols, entering the field and collecting data, conducting within and cross-case analysis, shaping hypotheses, enfolding literature and reaching closure (Eisenhardt, 1989). Similar to how following routines helps actors to make sense of the organizational tasks, using templates helps researchers to make sense of these theory-data-process interdependences.
Qualitative research templates 
QROM

16,2

Both templates and routines are commonly used for minimizing costs and maximizing the legitimacy of the involved organization or investigation (Feldman and Pentland, 2003). Similarly, the use of both templates and routines has been subject to criticisms regarding their allegedly standardized, repeatable nature and resultant inflexible disposition (Mees-Buss et al., 2020). In this viewpoint article, I offer a different perspective regarding the disposition of template usage. Although cursory observations might create an impression that routines are static objects, closer observations often reveal that routines are dynamic, flexible systems capable of change (Pentland and Reuter, 1994; Pentland and Feldman, 2005). Routines embody three necessary parts - the artifact (the physical indicators of specific actions present in the routine), the ostensive part (participants' understanding of the actions and the indicators) and the performative part (participants' agencies regarding actual implementation of the actions). All these parts interact with each other and are created and recreated through actions (Feldman and Pentland, 2003; Howard-Grenville et al., 2016).

Templates, similarly, are a collection of flexible, decipherable procedures developed through the opinions of experienced researchers, systematic reviews or Delphi techniques (Buus and Perron, 2020). The knowledge, prior experiences and perspectives of experienced researchers collectively contribute to the development of artifacts such as road-map actions, best-practice recommendations or checklist items (Sandelowski, 2015), which are physically indicated in templates. The expectations, regularities, understandings and the overall disposition of the researcher constitute the ostensive part. The performative part is tied to the agency of the researchers and the actual performances (Pentland and Feldman, 2005). All three parts of the templates are mutually constitutive. While the artifact parts of templates provide physical structures, how these artifacts are interpreted and used (the ostensive and performative parts) depends on the researcher. For instance, even if we consider a specific template, individual researchers can follow it in multiple, divergent ways. However, critics of qualitative templates often forget the ostensive and performative parts of the templates and focus merely on the artifacts.

The proponents of most qualitative templates do not advocate such a sole focus on the artifacts. To give an example, "Gioia methodology" has been renowned as a template for conducting inductive/abductive qualitative research. Many authors refer to the Gioia methodology guidelines collectively as the "Gioia template" (see Reay et al., 2019, p. 202; MeesBuss et al., 2020, p. 2 etc. for example). Denny Gioia has explicitly stated that "Gioia methodology" is to be considered as "systematic ways of thinking about ...qualitative research" and not as "formulaic presentational techniques" (Gehman et al., 2018, p. 293). This means that the researchers who apply the Gioia methodology in their own studies are expected to exercise the ostensive and performative parts of the template usage. Indeed, the template provides a structure and a starting point for conducting research. The users can apply the learned wisdom from the template into their own research. But ostensive and performative engagements will involve going beyond the mere application of a template, into the systematic perusal and problematization of the template's underlying paradigmatic and methodological suggestions to suit the research situation (Alvesson and Kärreman, 2013).

In fact, Gioia explicitly issued a disclaimer that his approach is not "a set of cookbook techniques" (Gehman et al., 2018; Gioia et al., 2013). I agree with the nonformulaic usage of templates as suggested by Gioia and colleagues. With regards to the cookbook analogy, the important distinction we need to recognize is the difference between cookbook techniques and the use of the cookbook. The use of a cookbook does not depend only on the cooking techniques mentioned in it (i.e. its artifacts). While cooking, the cookbook users exercise the ostensive part (their own reflections, interpretations and decisions regarding the recipes) and the performative part (their own ways of preparing the dish). Thereby they can try different measurements of the ingredients (extra pinch of spices here or less butter there), replace certain ingredients to suit the specific dietary requirements of a family member and develop 
their own personalized cooking techniques. Like how the techniques in a cookbook alone do not guarantee the preparation of a meal, the artifacts in a template alone do not promise the conduct of a qualitative study. The ostensive and performative parts play a part in the nonformulaic conduct of the qualitative research, as evidenced by studies using the same template being very different from each other. Let us examine the work of three researchers who applied Gioia methodology, as examples.

Examples of nonformulaic use of templates

I chose three management articles (i.e. Ladge et al., 2012; Strike and Rerup, 2016; Williams and Shepherd, 2016) as examples. Keeping the disciplinary context uniform was intentional, since it helped in providing a better illustration of the differences afforded by the ostensive and performative parts of template usage. The three selected articles explicitly mentioned the application of Gioia methodology in their published studies (refer Gioia et al., 2013 for further details about the methodology). However, none of these three articles displayed any evidence of mechanistic or formulaic research processes. In fact, the three articles clearly discussed the authors' expectations and ways of implementation of Gioia methodology. In the first article, Ladge et al. (2012) explored how women construct and react to images of possible multiple selves during the liminal period of pregnancy. The authors discussed the use of a grounded theory approach for data analysis. The data structure suggested by the Gioia methodology was used only to illustrate how the authors moved from key themes to conceptual categories. The data structure diagram detailed first-order concepts, second-order themes and the aggregate dimensions derived from the grounded theory-based data analysis.

In the second article, Strike and Rerup (2016) introduced the notion of mediated sensemaking and investigated how structural and contextual features and endogenous skills contributed to it. In their own words, their findings are in the form of a "grounded theoretical process theory" (Strike and Rerup, 2016, p. 880). Unlike Ladge and colleagues who used the Gioia methodology for creating a data structure, Strike and Rerup conducted their data analysis by using the Gioia methodology along with multiple case studies. They analyzed the data in seven phases using a two-person insider-outsider approach to theorizing and constant comparison. Then they presented the data in tables and conducted within- and cross-case analyses. Using the Gioia methodology, they developed a data structure detailing the first-order concepts, second-order themes and aggregate dimensions. The first-order concepts were informant-centric and used the informants' language while the second-order themes were researcher-centric. Recurring second-order themes were combined to derive the aggregate dimensions. To give an example, the first-order concepts "momentum" and "singlemindedness" were combined to form the second-order theme "entrapped frame", which in turn was combined with other similar themes ("lowering commitment" and "expanding frame") to derive the aggregate dimension "adaptive sensemaking".

Williams and Shepherd (2016) explored postdisaster new venture creation, its role in facilitating the resilience of community members and the reasons behind the effectiveness of some ventures over the others. The selection of cases, data collection and data analysis involved tapping into the subjective views and opinions of the community, the informants and the researchers. Through conversations with informants and people in the community as well as the examination of organizational documents, the authors developed a working definition of the potential ventures to be included in the sample. The initial selection criteria included four specifications - the ventures selected should be (1) emergent as a direct response to the needs of others, (2) emergent within the early postdisaster period, (3) a recognizable organization with emergent roles and transactions and (4) created and operated in the areas affected by the disaster. Through snowball sampling, six ventures which met these specifications were selected as the cases. Subsequently, the authors explored the postdisaster behavior of the members of these ventures using the Gioia methodology. 
QROM

16,2
The authors conducted multiple rounds of first-order and second-order coding. The firstorder coding was simultaneously informant-centric and researcher-centric since it included both the members' perspectives as well as the authors' initial interpretations. The authors used a code-and-rate approach to explore how cases differed across different codes. The firstorder concepts were then clustered into second-order themes. The cases were compared and contrasted on multiple second-order themes for identifying the sequences, linkages and boundary conditions. The authors thereby identified five aggregate dimensions, which arched over all the cases. Furthermore, they developed a timeline of events for each case and mapped the new dimensions onto that timeline.

These three examples show three different ways in which Gioia methodology was used. While Ladge et al. (2012) used a data structure inspired by the Gioia methodology, Strike and Rerup (2016) used it for data analysis alongside case study method. Although William and Shepherd (2016) also used both the Gioia methodology and case study method together, their approach was quite different to the one taken by Strike and Rerup. After deriving the aggregate dimensions, the former developed a timeline for each case. From these examples, it is clear that the presence of templates alone does not automatically make qualitative researchers mindless drones who unquestioningly apply the artifacts in a template. The problem is not with the template per se, but with the way it is used. Like how cookbook techniques contribute to cooking a dish, the research actions mentioned in a template (i.e. the artifacts) contribute to conducting a qualitative study only when the researcher's reflections, interpretations and agency (i.e. the ostensive and performative parts) are involved. The criticism against templates conveniently neglects the ostensive-performative relationship and treats the use of templates as functional and unreflective applications. If we (qualitative researchers) take this criticism at its face value, what we lose are opportunities to learn from templates. The diverse nature of qualitative research provides grounds for a lot of ambiguity, which often creates an uncomfortable paradigm shift for qualitative researchers, particularly the novices (Wagner et al., 2011). For relatively new researchers facing this uncomfortable shift, the templates will provide guidance on what conducting a qualitative study entails (Cao and Guo, 2015).

Usually, templates are a result of collective action and discussion among experienced methodologists and researchers. These templates will not only help in developing a shared mission in qualitative communities, but also will assist beginner or inexperienced researchers in understanding and undertaking qualitative research. Therefore, established mature qualitative researchers (the ones who no longer need a template to know what to do) must indeed develop templates based on their own personal experiences and methodological knowledge. Expecting novice researchers to fend for themselves and learn qualitative research on their own is inefficient. Instead, experienced researchers should aim for activating the collective empowerment of qualitative community through templates. Indeed, a problem will arise when such templates created by experienced researchers are considered as the final words. This rigidness associated with the use of templates is what makes them appear restraining. As an alternative to such methodological straightjackets, we should support flexible templates, which are open to redefinitions and reflexive use. It is up to the researchers to then reflect upon, interpret and apply the templates by varying, retaining or discarding aspects of the templates according to their specific research circumstances. This human agency to reflect and adjust the template to one's own specific use will prevent its formulaic application.

\section{Reflexive use of templates - an autoethnographic note}

Reflection denotes a practice of "engaging in comparison, considering alternatives, seeing things from various perspectives and drawing inferences" (Jordan et al., 2009, p. 466). 
Practicing reflection in qualitative research has been compared to entering a swamp. The solid ground would give way easily and make the researchers lose their balance and sometimes even drown (Finlay, 2002). How to reflect upon and see beyond templates is a question which requires much deliberation. There is no template for reflecting on templates. Reflecting on template usage in qualitative research is a gradual process, much like learning chess. Novice chess players learn the names of the chess pieces and the basic rules regarding their positions and movement. With hours of practice, as the players develop more competency and proficiency, they will be able to observe the opponents' moves and adjust their moves to contest the opponents' moves. Similarly, when researchers gain more research experience, they will develop more tacit and intuitive understandings about research situations and how to reflexively use and adapt templates to address such situations (Dreyfus and Dreyfus, 1980).

The process of reflecting upon templates that I suggest in this article is based on my own research experiences, initially as a $\mathrm{PhD}$ student and then as an Assistant Professor. When I reflect on my experiences since the beginning of my $\mathrm{PhD}$ candidacy, I realize that templates played an immense role in facilitating my learning of qualitative methodology. The explicit cataloging of informed choices, as suggested by templates, helped me in acquiring knowledge about different qualitative methods, understanding the involved methodological nuances, discerning the evolution and possible combinations of the methods and mindfully using the templates as starting points for designing and conducting qualitative studies. I discuss my reflexive use of templates below. Figure 1 gives a summary of the various stages of the reflexive use of templates discussed in this section.

I started my $\mathrm{PhD}$ in 2012, after almost three years of working as a banker. As a novice researcher, with no research background, each time I read a qualitative journal article I felt overloaded by its contents. Furthermore, my research involved textual analysis of published management research, which meant that reading journal articles was not only part of my literature review but also part of my data collection and analysis. Reading and processing the information in multiple qualitative articles was intellectually challenging in the beginning, especially since qualitative researchers often report the research processes in nonuniform ways. To make sense of the articles I was reading, first I identified the templates cited by the authors of different qualitative articles. For instance, several authors discussed their use of the steps and activities by Eisenhardt (1989) or the reports and research actions by Gibbert and Ruigrok (2010) in their case studies. Once I identified such templates, I examined the original methodological articles or books they belong to. Regarding the templates used by the aforementioned case studies, I checked out the Eisenhardt (1989) as well as the Gibbert and Ruigrok (2010) articles.

When I examined these templates, I first checked what the claimed purpose of each template is, i.e. whether it is a checklist for reporting or a road map for data collection and so on. For example, the Gibbert and Ruigrok (2010) template provides strategies for ensuring rigor in case studies. Once I determined the claimed purpose of the templates, I focused on the artifact parts, i.e. the research actions. Within any activity, be it the use of cookbooks, templates or routines, there are flexible aspects as well as indispensable aspects (Feldman, 2000). For example, an indispensable part of the hiring routine in an organization is providing the applicants job offers (or rejections). Similarly, while using the Gioia methodology for data analysis, the researchers will conduct first-order and second-order coding. Such indispensable research actions are usually integral to and will characterize particular research methods (Hammersley, 1999). To understand whether an aspect is indispensable or flexible, I manually checked and read the methodological literature discussed by the authors of the templates. To give an example, while examining the case study template offered by Gibbert and Ruigrok, I referred the works of Robert Yin (1981, 1994). Yin's works on
Qualitative research templates 
QROM

16,2

416
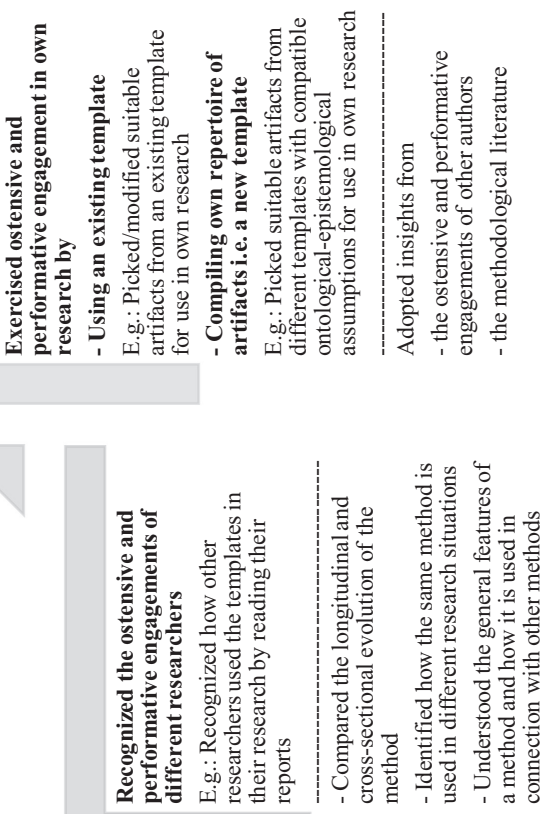

Figure 1.

Reflexive use of templates - an autoethnographic account

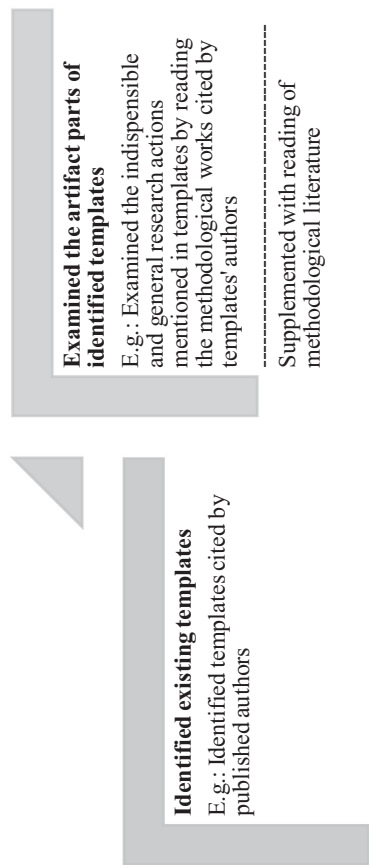


positivistic case studies had predominantly underpinned the template and were cited 21 times by Gibbert and Ruigrok (2010).

While examining the artifacts of the aforementioned templates, I also attempted to understand how published researchers engage the ostensive and performative parts of such templates. To understand this engagement, I read and reread qualitative management research articles to see how different authors interpret and adapt the templates to suit their own specific research purposes. One of the projects I undertook during my $\mathrm{PhD}$ involved an investigation of the reporting patterns in management grounded theory articles. During the course of this investigation, I examined various templates from the prior literature which focused on grounded theory (e.g. Kauffman and Denk, 2011). Using the artifact parts of these templates (e.g. Weiss et al., 2015) and by examining the ostensive and performative engagements by the authors of exemplar articles (e.g. Browning et al., 1995 - mentioned as an exemplar article in Suddaby, 2006), I compiled a repertoire of 27 research actions (Levinthal and Rerup, 2006) in management grounded theory research.

The repertoire compilation was not a mechanical process of eclectically compiling the artifacts of different templates. Rather, the compilation process involved acknowledging the stated purposes of the individual templates as well as understanding the philosophical assumptions underlying them. $\mathrm{My} \mathrm{PhD}$ research was underpinned by the critical realist perspective, which was based on the stance that there exists an external, independent reality which can only be known through the human mind and socially constructed meanings (Ritchie et al., 2013). Grounded theorists who follow a critical realist approach are normativethey draw on analytical categories from the prior literature, conduct theoretical sampling, allow conceptualization and reconceptualization through open coding and constant comparison, use multiple data collection and analysis approaches and aim to reach theoretical saturation (Oliver, 2012). Hence, to compile the aforementioned repertoire, I examined prior templates and grounded theory articles, which followed a critical realist perspective (Ralph et al., 2015). The repertoire included fundamental grounded theory research actions such as theoretical sampling, theoretical saturation, constant comparison, etc. as well as more general actions such as research questions, data collection method, triangulation, etc. This repertoire was then used as a new template for examining other published articles in management grounded theory research.

With the repertoire, I examined all the self-declared grounded theory articles published in ten top management journals (Academy of Management Journal, Journal of Management, MIS Quarterly, Journal of Applied Psychology, Journal of Operations Management, Administrative Science Quarterly, Organization Science, Personnel Psychology, Journal of International Business Studies and Strategic Management Journal) during the 1998-2017 time period. I noticed how the articles published during the 2008-2017 time period had discussed theoretical sampling, theoretical saturation, constant comparison and triangulation more often when compared to the previous decade (Nair and Gibbert, 2016). By manually checking the sample articles for explicit or implicit mentioning of each individual artifact in my repertoire and comparing different articles in a reflexive manner, I was able to learn how conducting and reporting management grounded theory research had evolved over time (Nair and Gibbert, 2016; Giddens, 1984; Rittle-Johnson and Star, 2011). Furthermore, by reading several articles which all used different variants of grounded theory, I realized that qualitative research methods can be attuned and contextualized to address different research situations. By doing so, I was able to understand the general features of the method rather than linking it only to a specific research situation.

To give an example, the authors of an article explored the considerations and issues that organizations examine while making business-to-business technology adoption decisions (see Asare et al., 2011). The authors used an inductive analysis process, which was in line with grounded theory (Glaser, 1978). However, grounded theory was not the sole method used in
Qualitative research templates 
QROM

16,2

418

the study. Overall, the authors had followed a phenomenological approach, which involved an exploration of the deeper meanings of respondents' experiences as encountered by themselves. Furthermore, to ensure that the analysis process could capture the people-centric nature of the study, the authors used a technique called domain analysis for integrating the identified themes. Domain analysis was more respondent-centric than conventional grounded theory analysis since it involved identifying, specifying and interrelating the main 'domains' as mentioned by the respondents (Atkinson and El Haj, 1996).

By using the repertoire while reading the article, I recognized how the authors had applied aspects of phenomenology, grounded theory and domain analysis together in one study. The authors had explicitly discussed how they followed the phenomenological approach (i.e. by engaging intensively with the participants through in-depth interviews). The analysis process involved two methods - grounded theory and domain analysis. The main analysis procedure was the open-axial-selective coding suggested by the grounded theory method. This involved labeling and reduction of data (open coding), identification of patterns and themes from the reduced data (axial coding) and integration of the formerly identified themes into central themes (selective coding). After selective coding, the authors used the domain analysis to provide a comprehensive view of the patterns and themes, which emerged out of the grounded theory-based analysis process.

In due course, I used this reflexive process to become familiar with different qualitative methods discussed in management research. I would iteratively examine templates, see how published authors discussed their usage and eventually create my own repertoire of research actions. The repertoires were constantly adopting inputs from the artifacts of other templates and ostensive and performative engagements of other authors. I also used the templates and the repertoires in my own investigations by adapting and refining them to suit my own research objectives and study circumstances. For instance, one of the earlier templates for building theories from case study research in management mentioned the use of hypotheses (Eisenhardt, 1989). However, hypotheses are developed usually in explanatory case studies. The case studies I conducted so far were descriptive or exploratory in nature and did not involve hypothesis development (Valikangas et al., 2015). Hence when I compiled a repertoire for case study method, I did not include hypothesis development in it.

At the end of my $\mathrm{PhD}$ candidacy, I had compiled repertoires for grounded theory, case study method as well as qualitative content analysis (Nair, 2018); the latter which was the predominant method used in my doctoral investigations. At this point, I also started working as an Assistant Professor. I started discussing the use of templates with the students of my introductory qualitative research course. These students were new to qualitative research. I discussed the plurality and flexibility of qualitative research with them in the first weeks of the course itself. The students were provided the repertoires (new templates) I had prepared during my $\mathrm{PhD}$ candidacy as well as templates developed by other researchers. Since reflections are enhanced by practices that mobilize dialogue and help in questioning assumptions (Jordan et al., 2009), the students were incited to deliberate upon the templates and their usage from the beginning of the course itself. They were advised to examine each template they encounter in the light of methodological literature (provided as reading and lecture material) and prior research (which they identified through a literature review). In this manner, the students were facilitated to engage the artifact part of the template usage while understanding the ostensive and performative engagements of other researchers. The students were encouraged to be critical, and there was no fear of retaliation for doing so, which helped in creating a reflective culture (Jordan et al., 2009).

The students were also required to conduct and report a research project of their own, in small project groups. As part of the project work, the students were allowed to adapt existing templates to suit their specific investigation, thus engaging the ostensive and performative parts of the template usage. The groups were also encouraged to compile their own 
repertoires by examining various templates, prior studies using such templates and the associated methodological literature. To equip students to reflexively engage with templates and the qualitative research process, I also provided lectures on reflexivity. The lectures urged the students to ask themselves questions such as "How is the template defining/ limiting/influencing the phenomenon under investigation?", "What is the rationale behind selecting specific courses of action discussed in the template?", "How can we consciously adjust the template to the research process?" "Can we make sense of the phenomenon/data in another way that what is suggested by the template?," etc. (Alvesson and Kärreman, 2013; Patnaik, 2013). This line of thinking encouraged the students to acknowledge the ostensive and performative parts of template usage.

Additionally, each project group had a peer group, which critically reviewed the work of the former on regular intervals. The peer groups often consisted of students with backgrounds in various disciplines such as psychology, sociology, political sciences, etc. The differences in disciplinary backgrounds provided the students opportunities for reflecting on the preunderstandings, vocabularies and assumptions underlying their template usage (Alvesson and Kärreman, 2013). For instance, majority of members in a particular project group had their background in psychology. Their peer group consisted of members with backgrounds in anthropology. Since psychology is a predominantly positivistic discipline (Breen and Darlaston-Jones, 2010), the former group was more interested in conducting a generalizable study. Hence, they ostensively engaged with templates which included empirical generalizability as an artifact. However, discussing with their peer group helped them understand that an interpretivistic approach is more suitable for answering their exploratory research question (which was about the cultural perceptions of manliness in two different communities). So the former group adjusted their engagement with the templates likewise.

Through regular consultation meetings, I monitored how the project groups and peer groups were working together. I met the groups every week and discussed their progress. Among other matters, I monitored how the groups examined the existing templates, understood their purpose and underlying assumptions, questioned their expectations and subsequently adopted/adapted such templates or created own repertoires. For instance, the use of photographs as data elicitation devices was discussed in a template provided to the students (based on Ritchie et al., 2013). The project groups understood the purpose of using photographs (i.e. to enable interviewees to talk during interviews). But some groups did not consider photo elicitation as a suitable technique for their own specific projects since they opined that this technique would involve asking the interviewees to share private photographs with the interviewers. Instead, they used music from the interviewees' home countries as a data elicitation technique.

The final project reports of the groups were required to discuss the steps and decisions taken during the research journey in full detail. The students were also graded on how they reflexively monitored (Giddens, 1984) the whole research process. I was able to grade this through my interactions with the students in the classroom as well as through reflexive essays, which the students had submitted for grading. The essays included reflexive accounts about various factors that affected the research outcomes and the research process, including the use of templates. The lectures, group work, peer feedback and consultation meetings equipped the students in developing a reflexive outlook regarding qualitative research and template usage. Grades were allotted on the basis of how deeply and extensively the reflections were performed. To give an example, a well-written reflexive essay had discussed how one of the artifacts suggested in a particular template (i.e. triangulation of interview data with archival data from college newspapers) was not optimal for their project since a preliminary check had revealed that the college newspapers did not provide any 
QROM

16,2 reliable new information. Figure 1 gives a summary of the various stages of the reflexive use of templates discussed in this section.

\section{Conclusion}

Through this article, I present my viewpoint and experiences regarding the use of templates in qualitative research. First, I submit that the criticisms against the use of templates should be reexamined. Understanding the purpose (e.g. reporting, designing, conducting) of the template and its proposed research actions will be highly helpful in making decisions regarding its use. Second, qualitative researchers should remember that templates (just like organizational routines) have three parts - the artifact, the ostensive and the performative. Forgetting the latter two parts is a major factor behind some of the criticisms against templates. The artifacts of the templates do assist the researcher in the research process. Concurrently, the researchers also have their own ostensive understanding and performative agency with respect to template usage. Ascribing importance to the artifact's role in qualitative research does not necessarily diminish the role of the ostensive and performative engagements of the researcher. The templates must accommodate a range of potential artifacts to allow for a researcher's subjective participation and subsequent problematization. The researchers, on their side, should use templates as revisable recommendations rather than rigid commands. In this manner, templates and researchers can coexist and cocreate high-quality qualitative management research. I submit that qualitative management research needs more of such reflexive usage of templates.

\section{References}

Alvesson, M. and Karreman, D. (2013), Qualitative Research and Theory Development: Mystery as Method, Sage Publications, London. doi: 10.4135/9781446287859.

Anderson, C. (2010), "Presenting and evaluating qualitative research", American Journal of Pharmaceutical Education, Vol. 74 No. 8, pp. 1-7.

Asare, A.K., Brashear Alejandro, T.G., Granot, E. and Kashyap, V. (2011), "The role of channel orientation in B2B technology adoption”, Journal of Business and Industrial Marketing, Vol. 26 No. 3, pp. 193-201.

Atkinson, S. and Haj, M.A.E. (1996), "Domain analysis for qualitative public health data”, Health Policy and Planning, Vol. 11 No. 4, pp. 438-442.

Barbour, R.S. (2001), "Checklists for improving rigour in qualitative research: a case of the tail wagging the dog?”, British Medical Journal, Vol. 322 No. 7294, pp. 1115-1117.

Becker, M.C. (2004), "Organizational routines: a review of the literature”, Industrial and Corporate Change, Vol. 13 No. 4, pp. 643-678.

Breen, L.J. and Darlaston-Jones, D. (2010), "Moving beyond the enduring dominance of positivism in psychological research: implications for psychology in Australia”, Australian Psychologist, Vol. 45 No. 1, pp. 67-76.

Browning, L.D., Beyer, J.M. and Shetler, J.C. (1995), "Building cooperation in a competitive industry: SEMATECH and the semiconductor industry", Academy of Management Journal, Vol. 38 No. 1, pp. 113-151.

Buus, N. and Perron, A. (2020), "The quality of quality criteria: replicating the development of the consolidated criteria for reporting qualitative research (COREQ)", International Journal of Nursing Studies, Vol. 102, 103452.

Cao, C. and Guo, S. (2015), "Genre analysis and advanced English teaching", Theory and Practice in Language Studies, Vol. 5 No. 12, pp. 2613-2618. 
Denzin, N.K. (2009), "The elephant in the living room: or extending the conversation about the politics of evidence", Qualitative Research, Vol. 9 No. 2, pp. 139-160.

Dreyfus, S.E. and Dreyfus, H.L. (1980), A Five-state Model of the Mental Activities Involved in Directed Skill Acquisition. Operation Research Center Report, University of California, Berkeley, CA.

Eisenhardt, K.M. (1989), "Building theories from case study research", Academy of Management Review, Vol. 14 No. 4, pp. 532-550.

Feldman, M.S. (2000), "Organizational routines as a source of continuous change", Organization Science, Vol. 11 No. 6, pp. 611-629.

Feldman, M.S. and Pentland, B.T. (2003), "Reconceptualizing organizational routines as a source of flexibility and change", Administrative Science Quarterly, Vol. 48 No. 1, pp. 94-118.

Finlay, L. (2002), "Negotiating the swamp: the opportunity and challenge of reflexivity in research practice", Qualitative Research, Vol. 2 No. 2, pp. 209-230.

Gehman, J., Glaser, V.L., Eisenhardt, K.M., Gioia, D., Langley, A. and Corley, K.G. (2018), "Finding theory-method fit: a comparison of three qualitative approaches to theory building", Journal of Management Inquiry, Vol. 27 No. 3, pp. 284-300.

Gibbert, M. and Ruigrok, W. (2010), "The 'what' and 'how' of case study rigor: three strategies based on published work", Organizational Research Methods, Vol. 13 No. 4, pp. 710-737.

Giddens, A. (1984), The Constitution of Society, Polity, Cambridge.

Gioia, D.A., Corley, K.G. and Hamilton, A.L. (2013), "Seeking qualitative rigor in inductive research: notes on the Gioia methodology", Organizational Research Methods, Vol. 16 No. 1, pp. 15-31.

Glaser, B.G. (1978), Advances in the Methodology of Grounded Theory: Theoretical Sensitivity, Sociology Press, Mill Valley CA.

Glaser, B.G., Strauss, A.L. and Strutzel, E. (1968), "The discovery of grounded theory; strategies for qualitative research", Nursing Research, Vol. 17, p. 364.

Google Scholar (2021), available at: https://scholar.google.com/ (accessed 8 February 2021).

Hammersley, M. (1999), "Not bricolage but boatbuilding: exploring two metaphors for thinking about ethnography", Journal of Contemporary Ethnography, Vol. 28 No. 5, pp. 574-585.

Harley, B. and Cornelissen, J. (2020), "Rigor with or without templates? The pursuit of methodological rigor in qualitative research”, Organizational Research Methods. doi: 10.1177/ 1094428120937786.

Howard-Grenville, J.A., Rerup, C., Langley, A. and Tsoukas, H. (Eds), (2016), Organizational Routines: How They Are Created Maintained and Changed, Oxford University Press, Oxford, Vol. 5.

Joanna Briggs Institute (2017), "Checklist for qualitative research", The Joanna Briggs Institute Critical Appraisal Tools for Use in JBI Systematic Reviews, Adelaide.

Jordan, S., Messner, M. and Becker, A. (2009), "Reflection and mindfulness in organizations: rationales and possibilities for integration”, Management Learning, Vol. 40 No. 4, pp. 465-473.

Kaufmann, L. and Denk, N. (2011), "How to demonstrate rigor when presenting grounded theory research in the supply chain management literature", Journal of Supply Chain Management, Vol. 47, pp. 64-72.

Köhler, T., Smith, A. and Bhakoo, V. (2019), "Feature topic for ORM: 'templates in qualitative research methods", Organizational Research Methods, Vol. 22 No. 1, pp. 3-5.

Ladge, J.J., Clair, J.A. and Greenberg, D. (2012), "Cross-domain identity transition during liminal periods: constructing multiple selves as professional and mother during pregnancy", Academy of Management Journal, Vol. 55 No. 6, pp. 1449-1471.

Langley, A. and Abdallah, C. (2011), "Templates and turns in qualitative studies of strategy and management”, Building Methodological Bridges, Emerald Group Publishing.

Levinthal, D. and Rerup, C. (2006), "Crossing an apparent chasm: bridging mindful and less-mindful perspectives on organizational learning”, Organization Science, Vol. 17 No. 4, pp. 502-513.
Qualitative research templates

\section{$\longrightarrow$}


QROM 16,2
Locke, K., Feldman, M. and Golden-Biddle, K. (2020), "Coding practices and iterativity: beyond templates for analyzing qualitative data", Organizational Research Methods. doi: 10.1177/ 1094428120948600.

Manuj, I. and Pohlen, T.L. (2012), “A reviewer's guide to the grounded theory methodology in logistics and supply chain management research", International Journal of Physical Distribution and Logistics Management, Vol. 42 Nos 8-9, pp. 784-803.

Mees-Buss, J., Welch, C. and Piekkari, R. (2020), "From templates to heuristics: how and why to move beyond the Gioia methodology", Organizational Research Methods. doi: 10.1177/1094428120967716.

Nair, L.B. (2018), "Appraising scholarly impact using directed qualitative content analysis: a study of article title attributes in management research", SAGE Research Methods Cases. doi: 10.4135/ 9781526444141, ISBN: 9781526444141.

Nair, L.B. (2020), "From 'whodunnit' to 'how': detective stories and auditability in qualitative business ethics research”, Journal of Business Ethics. doi: 10.1007/s10551-020-04479-4.

Nair, L.B. and Gibbert, M. (2016), "Hot on the audit trail: how to assess methodological transparency of grounded theory in management?", Academy of Management Annual Meeting, August, 2016, Anaheim. doi: 10.5465/ambpp.2016.13758abstract.

Oliver, C. (2012), "Critical realist grounded theory: a new approach for social work research", British Journal of Social Work, Vol. 42 No. 2, pp. 371-387.

Orton, J.D. (1997), "From inductive to iterative grounded theory: zipping the gap between process theory and process data", Scandinavian Journal of Management, Vol. 13, pp. 419-438.

Patnaik, E. (2013), "Reflexivity: situating the researcher in qualitative research", Humanities and Social Science Studies, Vol. 2 No. 2, pp. 98-106.

Pentland, B.T. and Feldman, M.S. (2005), "Organizational routines as a unit of analysis", Industrial and Corporate Change, Vol. 14 No. 5, pp. 793-815.

Pentland, B.T. and Reuter, H.H. (1994), "Organisational routines as grammars of action", Administrative Science Quarterly, Vol. 39, pp. 484-510.

Ralph, N., Birks, M. and Chapman, Y. (2015), "The methodological dynamism of grounded theory", International Journal of Qualitative Methods, Vol. 14 No. 4, pp. 1-6.

Reay, T., Zafar, A., Monteiro, P. and Glaser, V. (2019), "Presenting findings from qualitative research: one size does not fit all!", The Production of Managerial Knowledge and Organizational Theory: New Approaches to Writing, Producing and Consuming Theory, Emerald Publishing.

Ritchie, J., Lewis, J., Nicholls, C.M. and Ormston, R. (Eds) (2013), Qualitative Research Practice: A Guide for Social Science Students and Researchers, Sage Publishers.

Rittle-Johnson, B. and Star, J.R. (2011), "The power of comparison in learning and instruction: learning outcomes supported by different types of comparisons", Psychology of Learning and Motivation, Academic Press, Vol. 55, pp. 199-225.

Sandelowski, M. (2015), “A matter of taste: evaluating the quality of qualitative research", Nursing Inquiry, Vol. 22 No. 2, pp. 86-94.

Sonpar, K., Pazzaglia, F. and Kornijenko, J. (2010), "The paradox and constraints of legitimacy", Journal of Business Ethics, Vol. 95 No. 1, pp. 1-21.

Strauss, A. and Corbin, J. (1998), Basics of Qualitative Research: Procedures and Techniques for Developing Grounded Theory, Sage, Thousand Oaks CA.

Strike, V.M. and Rerup, C. (2016), "Mediated sensemaking”, Academy of Management Journal, Vol. 59 No. 3, pp. 880-905.

Suddaby, R. (2006), "From the editors: what grounded theory is not", Academy of Management Journal, Vol. 49 No. 4, pp. 633-642.

Tong, A., Sainsbury, P. and Craig, J. (2007), "Consolidated criteria for reporting qualitative research (COREQ): a 32-item checklist for interviews and focus groups", International Journal for Quality in Health Care, Vol. 19 No. 6, pp. 349-357. 
Valikangas, L., Gibbert, M., Nair, L.B., Paukku, M. and Peixoto, I. (2015), Strategic Innovation. The Definitive Guide to Outlier Strategies, Pearson-Financial Times Press, Old Tappan, NJ, ISBN -13: 978-0133989441, -10: 0133989445.

Van Maanen, J., Sørensen, J.B. and Mitchell, T.R. (2007), "The interplay between theory and method", Academy of Management Review, Vol. 32, pp. 1145-1154.

Wagner, C., Garner, M. and Kawulich, B. (2011), "The state of the art of teaching research methods in the social sciences: towards a pedagogical culture", Studies in Higher Education, Vol. 36 No. 1, pp. $75-88$.

Weatherall, R. (2019), "Writing the doctoral thesis differently", Management Learning, Vol. 50 No. 1, pp. 100-113.

Webster, M. (2020), "Routine”, available at: https://www.merriam-webster.com/dictionary/routine.

Weiss, M., Nair, L.B., Gibbert, M. and Koepplin, H. (2015), "What passes as a transparent field study in management?", Academy of Management Proceedings, Vol. 2015 No. 1, p. 10236, ISSN (print): 0065-0668, ISSN (online): 2151-6561.

Williams, T.A. and Shepherd, D.A. (2016), "Building resilience or providing sustenance: different paths of emergent ventures in the aftermath of the Haiti earthquake", Academy of Management Journal, Vol. 59 No. 6, pp. 2069-2102.

Yin, R.K. (1981), "The case study crisis: some answers", Administrative Science Quarterly, Vol. 26 No. 1, pp. 58-65.

Yin, R.K. (1994), Case Study Research: Design and Methods, Sage, London.

\begin{abstract}
About the author
Lakshmi Balachandran Nair is an Assistant Professor at the Department of Business and Management of LUISS Guido Carli University (Rome, Italy). Lakshmi's primary areas of expertise are qualitative methodology and research ethics. She has published in various journals including Organizational Research Methods, Journal of Business Ethics, Journal of Business Research, Journal of Management Inquiry, Research Synthesis Methods, Scientometrics, etc. to name a few. For her work she has received various honors including Academy of Management Best Paper Award (2014), Interdisciplinary Social Sciences Emerging Scholar Award (2018), British Academy of Management Best Full Paper Award (2018), and ECRM Innovation in Teaching of Research Methodology Excellence Award (2019). Lakshmi Balachandran Nair can be contacted at: 1balachandrannair@luiss.it
\end{abstract}

For instructions on how to order reprints of this article, please visit our website:

www.emeraldgrouppublishing.com/licensing/reprints.htm

Or contact us for further details: permissions@emeraldinsight.com 